\title{
Molecular genetic approaches to identification, epidemiology and taxonomy of non-albicans Candida species
}

\author{
D. J. SULLIVAN* $\dagger$, M. C. HENMAN $\ddagger$, G. P. MORAN* $\dagger$, LORRAINE C. O'NEILL $\dagger$, \\ DÉSIRÉE E. BENNETT*†, D. B. SHANLEY* and D. C. COLEMAN*†\$ \\ * University of Dublin, School of Dental Science, Department of Oral Medicine and Pathology, †The Moyne \\ Institute, Department of Microbiology and $\ddagger$ School of Pharmacy, Department of Pharmacology, Trinity College, \\ Dublin 2, Republic of Ireland
}

\begin{abstract}
The reported incidence of fungal infections associated with non-albicans species from the Candida genus is increasing. Most of these infections occur in immunocompromised patients, particularly those infected with HIV. The role of molecular genetic techniques alongside the existing techniques for the identification and typing of these organisms is discussed. Species-specific genomic DNA fragments cloned from $C$. tropicalis and $C$. krusei have been developed for identification and strain typing. Analysis of tRNA profiles has been shown to be effective for the identification of $C$. glabrata, $C$. guilliermondii, $C$. parapsilosis and $C$. tropicalis. A PCR method employing primers complimentary to large ribosomal subunit genes and the lanosterol- $\alpha$-demethylase gene has been applied for several species, including $C$. glabrata, $C$. krusei and $C$. tropicalis. Strain typing by comparison of genomic DNA fingerprints has been demonstrated for $C$. tropicalis and $C$. krusei following hybridisation analysis with species-specific probes. Synthetic oligonucleotide probes-which do not have to be species-specific and which can detect minor polymorphisms-have also been used for strain typing of isolates of several non-albicans species. Random amplification of polymorphic DNA (RAPD) has also been used for analysis of $C$. glabrata, $C$. lusitaniae and $C$. tropicalis isolates. The potential for the application of these and other techniques to Candida spp. taxonomyand the example of a recently discovered novel species, $C$. dubliniensis-is discussed.
\end{abstract}

\section{Introduction}

The increased interest of the scientific and medical communities in Candida spp. reflects directly a steady rise in the number of reports on the incidence of Candida infections in man over the past decade. This is related largely to a dramatic increase in the number of individuals with deficient cellular immunity, in particular those infected with HIV and individuals receiving immunosuppressive treatments, both in organ transplantation and in anti-cancer therapy. C. albicans is the most pathogenic member of the genus Candida and the most frequent cause of candida infection [1]. However, in recent years, species of Candida other than $C$. albicans have been implicated more frequently in human disease, although many reports describing cases of candida infection by non-albicans Candida spp. provide insufficient data to establish a causal relationship between the species isolated and the infection.

Received 29 Sept. 1995; accepted 26 Oct. 1995. §Correspondence should be sent to Dr D. C. Coleman.
Whether the widespread use of antifungal drugs has contributed to an increased incidence of non-albicans Candida organisms being isolated from HIV-positive and AIDS patients remains an open question. In the few reports that have commented on this possibility, some [2-4], but not all $[5,6]$, consider that antifungal drug therapy makes a significant contribution. However, only a few studies have used molecular techniques to identify or type the organisms involved, and given that there are many other clinical and methodological differences, it is beyond the scope of this review to carry out a detailed comparison of these studies. However, the data from our collection of isolates suggest that, with long-term treatment, changes in the prevalence of $C$. albicans strains and other Candida spp. occur more frequently, and that many of these organisms are less susceptible to azole antifungal agents $[3,7]$. Whether this is of relevance to the patient's clinical condition has yet to be answered.

The reported high rate of relapse of candida infection in immunocompromised patients points strongly to the 
need for detailed epidemiological investigations of the organisms responsible $[7,8]$. The purpose of this review is to describe the development and application of molecular techniques for the analysis of nonalbicans Candida spp. involved in clinical disease. After a brief description of the clinically relevant species, the processes of culture, species identification and strain typing are discussed, followed by consideration of the taxonomy of Candida spp. since, at present, there are a number of confusing anomalies that molecular techniques could resolve.

\section{Clinically important non-albicans Candida species}

According to Barnett et al. [9], there are 166 species in the genus Candida (Berkhout), but only a small proportion of these is found in man, and of these only a handful pose clinical problems. Several non-albicans Candida spp. are known to be pathogenic and are responsible for disease in man, while several others cause disease occasionally (Table 1 ). These organisms are responsible most commonly for chronic superficial infections of skin, nails and mucosal surfaces. Less frequently, they can disseminate and cause lifethreatening systemic (or deep-seated) disease, and it is these infections that present the greatest challenge to clinicians. Of the superficial forms of infection, oral candidosis is the most important and frequent form encountered in HIV-infected individuals [7, 10, 20, 21], whereas vulvovaginal candidosis is often encountered in otherwise apparently healthy women [1]. Systemic candida infections, although relatively rare, show the versatility of the genus in the range of internal organs that can be infected, and there has been a dramatic increase in the incidence of disseminated candidosis in

Table 1. Non-albicans Candida spp. responsible for opportunist infections

\begin{tabular}{|c|c|}
\hline Species* & References \\
\hline $\begin{array}{l}\text { Common opportuni } \\
\text { C. dubliniensis } \dagger \\
\text { C. guillermondii } \\
\text { C. kefyr } \\
\text { C. krusei } \\
\text { C. lusitaniae } \\
\text { C. parapsilosis } \\
\text { C. tropicalis }\end{array}$ & $\begin{array}{c}1,2,4,10,11,12,13 \\
14,15,16,17,18\end{array}$ \\
\hline $\begin{array}{l}\text { Rare opportunist } \mathrm{p} \\
\text { C. famata } \\
\text { C. holmii } \\
\text { C. inconspicua } \\
\text { C. norvegensis } \\
\text { C. rugosa } \\
\text { C. utilis } \\
\text { C. zeylanoides }\end{array}$ & $1,4,16,19$ \\
\hline
\end{tabular}

\footnotetext{
${ }^{*}$ Listed in alphabetical order.
}

$\dagger C$. dubliniensis is a novel species of Candida that is present in around one-third of oral isolates from HIV-infected patients in our population and has been isolated from other subjects and in other countries; see text for details. the last two decades [11]. However, the clinical manifestations of diseases caused by different pathogenic Candida spp. are usually indistinguishable. A complex interplay between multiple strains and species can occur in both superficial and systemic infections, thus making it difficult to determine the contribution, if any, of individual organisms to infection $[3,4,12,13]$.

\section{Identification of non-albicans Candida species from clinical specimens}

\section{Culture and identification}

It is important to be able to distinguish candida infections from those caused by other yeasts and fungi. Furthermore, since several non-albicans Candida spp. are inherently less susceptible to commonly used antifungal drugs $[6,22]$, their rapid identification is essential if the most appropriate therapeutic approach is to be used. The selection of media for the growth and isolation of Candida spp. from clinical specimens is of critical importance [7]. Ideally the medium used should sustain the growth of all the Candida spp. found commonly in clinical specimens and should prohibit the growth of bacteria. The medium should not interfere with the viability of the organisms and should facilitate the identification of clinical specimens harbouring mixtures of yeast species. Traditionally, various preparations of Sabouraud-dextrose agar, often supplemented with antibiotics to further suppress bacterial growth, are used for this purpose [7, 23]. However, this medium is not differential and is not useful for distinguishing between different Candida spp. present in the same clinical specimen [24]. Four different media have been described which distinguish C. albicans from other yeast species on the basis of colony colour or morphology, or both, including Pagano-Levin agar [25] (a medium that contains triphenyltetrazolium chloride incorporated into Sabouraud agar), phosphomolybdate agar [26, 27], Nickerson's medium [28] and CHROMagar Candida [29]. All these media are useful for identifying clinical specimens containing mixtures of $C$. albicans and other yeast species $[24,29]$. CHROMagar Candida-a newly developed commercially available medium-has an additional advantage in that it allows the presumptive identification of $C$. albicans, $C$. tropicalis and $C$. krusei [29]. We use potato dextrose agar as the standard culture medium for the isolation of Candida spp. from clinical specimens and have found that it is particularly useful for distinguishing between colonies of different yeast species from the same clinical specimen [7].

After primary isolation, the number and relative abundance of distinct yeast colony types, including colonies with distinct morphologies or colours, depending on the media employed, should be recorded. Representatives of each colony type should then be purified and the species to which they belong identified [7]. C. albicans isolates can be differen- 
tiated from other yeast isolates by the ability of the former to form germ tubes and chlamydospores [7].

Isolates of individual species of the genus Candida are identified classically on the basis of physiological and biochemical reactions and a limited number of morphological features [1]. Commercially available yeast identification kits record the ability of isolates to assimilate a variety of compounds that can be used as sole sources of carbon or nitrogen [1]. However, in practice there are a number of problems associated with the interpretation of these results $[30,31]$. Particular assimilation test results may not be consistent because the same isolate could yield a positive test result on one occasion and a negative test result on another. Phenotypic switching or the existence of a mixture of metabolic variants are possible reasons for this [7,32]. Furthermore, genetically diverse species of yeast can yield similar substrate utilisation profiles, resulting in poor discrimination between unrelated yeast species if the profile is the sole means of identification. The pattern of results from such a procedure provides a list of species in order of their probability. When these results are taken together with morphological and serological test results, the likelihood of an accurate identification is increased greatly.

An excellent example of the difficulties that can be encountered in identification was found while investigating populations of oral Candida isolates from HIV-infected individuals with the API ID 32C yeast identification kit [33]. According to the API APILAB database, the ID $32 \mathrm{C}$ profiles of these isolates corresponded to poor identification, in decreasing order of probability, of $C$. sake, C. albicans 2 (i.e., $C$. stellatoidea) and $C$. albicans 1 . These organisms formed germ tubes and chlamydospores, and were therefore thought initially to be unusual isolates of $C$. albicans or $C$. stellatoidea [7]. Preliminary phenotypic and genetic characterisation of several of these isolates in Dublin suggested that they could also constitute a novel species of Candida [33]. Subsequent detailed analysis demonstrated that this was likely to be the case (see below).

\section{Molecular identification of Candida spp.; use of molecular techniques}

It takes a minimum of $24-48 \mathrm{~h}$ to culture and identify a species of Candida from a clinical specimen by conventional mycological procedures [7] and, even then, there may be some difficulty in identifying some isolates definitively (see above). Therefore, there is a compelling need for rapid, sensitive and specific tests to aid in the diagnosis of candida infections, especially disseminated infections. Several molecular procedures have been applied to a small number of Candida spp., and the majority of these have been performed in vitro with DNA extracted from cultured organisms, with the ultimate intention of further development for application directly to clinical specimens, thus obviating the necessity for culture [34-45].

One of the first approaches involved restriction fragment length polymorphism (RFLP) analysis of fragments obtained by restriction endonuclease digesion of genomic DNA from Candida spp. and subsequent separation of the fragments by agarose gel electrophoresis [7, 34, 46, 47]. However, RFLP analysis of total genomic DNA from both bacteria and fungi can result in the generation of complex patterns of fragments that are ambiguous and difficult to interpret objectively [7]. RFLP patterns obtained from Candida spp. with the restriction endonuclease $E c o \mathrm{R} 1$ (used in the majority of studies) contain only a limited number of bands that are suitable for analysis [7]. The low precision of RFLP analysis, coupled with concern over its reliability, means that it is not suitable for species identification [7].

A second molecular approach to the identification of Candida spp. involves Southern hybridisation analysis. Several C. albicans-specific DNA sequences and genes have been used as molecular probes to identify this organism in vitro $[7,48,49]$, and similar speciesspecific DNA probes have been developed for the molecular identification of $C$. tropicalis and $C$. krusei $[13,42,50]$. Unfortunately, hybridisation analysis involves several time-consuming steps and can take $\geqslant 24 \mathrm{~h}$ to yield a result. Furthermore, detection of non-amplified $C$. albicans target DNA by Southern hybridisation has a detection limit of $\left(5 \times 10^{2}\right)$ $\left(1 \times 10^{5}\right)$ blastoconida [51, 52].

A third molecular technique involves tRNA profile analysis [53]. This technique is based on the electrophoretic pattern of total cellular tRNA samples from cultured organisms. The profiles generated are analysed by high-resolution semi-denaturing ureaPAGE, followed by methylene blue staining. It has been demonstrated that reproducible and strain-independent species-specific tRNA profiles can be obtained for the species $C$. albicans, C. tropicalis, $C$. parapsilosis, C. guilliermondii and C. glabrata. Again, this technique takes at least one working day to yield results after the test organisms have been cultured in the laboratory.

The approach that offers the greatest potential in precision, sensitivity and speed involves the application of PCR technology [54] to amplify target DNA sequences by thermostable DNA polymerase-mediated extension of specific oligonucleotide primers. Theoretically, it should be possible to design PCR tests that are capable of detecting any of the clinically important pathogenic species of Candida in a few hours by employing primers complimentary to DNA sequences that are common but unique to these organisms as a group. Subsequently, it should be possible to identify 
individual species with species-specific primers. PCR has been used in several recent studies to facilitate the detection of particular Candida spp. in vitro and in clinical specimens with primers complimentary to various genes and multicopy DNA elements, including the $C$. albicans heat shock protein 90 gene (HSP 90) [39], the cytochrome P-450 lanosterol- $\alpha$-demethylase gene [41], 5S rDNA sequences [44] and the $C$. albicans EO3 element [38]. Primers generated from the HSP 90, 5S rDNA and EO3 sequences have been used only in the detection of $C$. albicans. Other studies, employing primers complimentary to large ribosomal subunit sequences, have demonstrated that PCR can be applied successfully to the rapid in-vitro identification (several hours) of the non-albicans Candida spp. encountered most frequently, including C. tropicalis, C. glabrata, C. krusei and C. parapsilosis (K. A. Haynes and T. J. Westerneng, personal communication). Species-specific primers have also been developed to detect purified DNA from $C$. albicans, C. tropicalis, C. glabrata and C. krusei, based on a highly variable region of the lanosterol- $\alpha$ demethylase gene from these organisms [41]. These primers were found to be specific for their target species, with the exception of the $C$. glabrata primers which also gave a weak positive reaction with $C$. parapsilosis DNA. Primers complimentary to sequences from a conserved region of the lanosterol- $\alpha$ demethylase gene yielded positive PCR reactions with purified DNA from various Candida spp. and also allowed the detection of purified DNA from Cryptococcus neoformans and Trichosporon beigelii [41]. However, when the primers for $C$. albicans and $C$. glabrata were used to detect cells in clinical samples, it was found that PCR was less sensitive than culturebased techniques. Other problems associated with the technique include false-negative results with particular samples, such as thick pus, where DNA extraction can be difficult, and false-positive results caused by contamination of specimens with the normal flora of patients $[41,44,45]$, thereby emphasising that PCR technology is limited currently to the detection of Candida organisms in samples from normally sterile sites such as blood and peritoneal fluid. Despite these limitations, the application of PCR technology to the detection and identification of Candida spp. in clinical material is at an early stage of development, and the potential for the technique is still tremendous given its rapidity. Further research in this area is required, including the development of quantitative PCR techniques for sensitive, efficient and specific tests for routine clinical application.

Another potential method for species identification involves the synthesis of oligonucleotide probes complimentary to portions of the internal transcribed spacer regions of rDNA. This has been shown to be effective for $C$. albicans identification and would be equally applicable to non-albicans spp. [55]. A disadvantage of the technique for routine use is that the sequence of the internal spacer regions must be determined before a species-specific probe can be developed.

\section{Candida strain typing}

An ability to distinguish between separate isolates of the same Candida spp. is essential for epidemiological investigations. Accurate typing of Candida isolates can provide valuable information regarding the source of a particular infection, it can facilitate the detection of multiple strains in a clinical specimen or the detection of the same or different strains from recurrent episodes of infection in individual patients. Furthermore, strain typing can provide valuable population information about isolates of the same Candida spp. from separate individuals and patient groups. Over the last 20 years, a wide variety of typing methods has been applied to $C$. albicans isolates and, to a lesser extent, isolates of nonalbicans Candida spp. [7]. Most of these typing methods are based on phenotypic characters, many of which are not very discriminatory or exhibit poor reproducibility, or both. The ability of many Candida spp. to exhibit phenotypic variation can limit the usefulness of these techniques [7, 56]. In an attempt to overcome these shortcomings, several of the molecular approaches used for species identification have also been applied to non-albicans Candida spp.

\section{Molecular approaches for typing non-albicans Candida species}

The same limitations that restrict the usefulness of RFLP analysis for identification of Candida spp. also pertain to strain discrimination by this technique. However, a number of studies have shown that RFLP patterns generated by the restriction endonuclease $H$ in fl can contain several well-resolved fragments of high mol. wt that can be used effectively for strain discrimination $[34,42,57]$. A variant of this technique is the digestion of intact chromosomal DNA by restriction endonucleases that cleave DNA infrequently, thereby giving rise to large DNA fragments that can be separated by pulsed-field gel electrophoresis and subjected to RFLP analysis. Studies with isolates of C. tropicalis, C. parapsilosis and C. lusitaniae have shown that this improves the efficiency of discrimination between isolates [58-60]. This technique is not suitable for routine application to clinical specimens because of its complexity.

Another molecular approach that has been used extensively to type isolates of $C$. albicans $[7,48,61,62]$ and, to a lesser degree, isolates of individual non-albicans Candida spp., involves fingerprint analysis with species-specific DNA probes. Restriction endonuclease-digested total cellular DNA is separated by electrophoresis and transferred to a membrane filter support, followed by Southern 
hybridisation with a labelled species-specific probe homologous to repetitive DNA sequences which are non-contiguous or dispersed throughout the genome. The use of such probes ensures the generation of hybridisation patterns consisting of multiple bands for improved isolate discrimination. Comparison of the patterns obtained with DNA from different isolates can then be used as a basis for differentiating between individual strains. This type of approach has been used successfully to discriminate between isolates of C. tropicalis with a cloned C. tropicalis-specific repeat sequence probe termed Ct13-8 [13], and between isolates of $C$. krusei with a cloned $C$. krusei-specific probe termed $\mathrm{CkF1}, 2$ [42]. The technique has excellent specificity and precision, and the profiles obtained are suitable for computerised storage and analysis. However, a disadvantage of the technique is that a different DNA probe is required for each species of Candida.

The use of DNA fingerprinting analysis of genomic DNA for typing isolates of non-albicans Candida spp. has been extended by the application of synthetic oligonucleotides composed of short repetitive sequence motifs as molecular fingerprinting probes [33]. All eukaryotic genomes contain multiple copies of short tandemly repeated microsatellite sequences which are excellent markers for the detection of genomic variation $[7,63-66]$. By using short oligonucleotide probes complimentary to these sequences, including $(\mathrm{GGAT})_{4},(\mathrm{GACA})_{4},(\mathrm{GATA})_{4},(\mathrm{GTG})_{5}$ and $(\mathrm{GT})_{8}$, informative DNA fingerprint profiles consisting of multiple hybridisation bands-ranging in size from $c .100 \mathrm{bp}$ to $c .20 \mathrm{~kb}$ for isolates of C. tropicalis, $C$. glabrata, C. krusei, C. dubliniensis and Cryptococcus neoformans - can be obtained [18,33,67]. This approach has several major advantages over conventional DNA fingerprint analysis with species-specific probes. Firstly, a set of probes can be used to fingerprint isolates from a range of different Candida and other fungal spp. without the necessity for species-specific probes. The optimal combination of oligonucleotide probe and restriction endonuclease for the most informative and discriminatory fingerprints with particular species are best determined empirically [33]. Secondly, several distinct fingerprints of the same isolate can be obtained by sequential hybridisation of the same restriction endonuclease-digested genomic DNA sample, thereby increasing the sensitivity and hence the discriminatory powers of the procedure greatly [33]. Furthermore, the technique is sufficiently sensitive to allow detection of minor polymorphisms among populations of closely related isolates from the same clinical specimen [33].

Karyotype analysis has also been used to type isolates belonging to several non-albicans species of Candida $[7,15,18,36,68-73]$. This procedure compares patterns of chromosomal DNAs obtained following their electrophoretic separation according to size in agarose gels by pulsed-field electrophoresis. This approach has been used extensively with isolates of $C$. albicans, $C$. glabrata and $C$. parapsilosis and has been shown to be of benefit. However, there are significant disadvantages, in comparison with other procedures, that render it unsuitable for routine analysis of large numbers of clinical isolates. The method requires expensive and highly specialised equipment; individual experiments can involve electrophoretic separation times of several days; and the preparation of yeast chromosomal DNA samples before electrophoresis is both tedious and time consuming.

PCR technology has also been applied to strain discrimination within several species of Candida $[18,33,37,74]$. Potentially, one of the most useful PCR approaches is random amplification of polymorphic DNA (RAPD) analysis [75-78]. RAPD involves PCR amplification of target genomic DNA sequences with one or more short oligonucleotide primers, followed by separation of the amplimers by agarose gel electrophoresis. The primer sequence is selected at random and the most suitable primers for a particular species have to be determined empirically. In a number of recent studies, distinctive PCR profiles consisting of multiple amplified fragments were obtained by RAPD with isolates of $C$. albicans, $C$. tropicalis, C. glabrata, C. lusitaniae and C. dubliniensis $[18,37]$. Furthermore, in one recent study a physiologically homogeneous collection of $C$. parapsilosis isolates was differentiated into three distinct groups by RAPD analysis [37]. In several cases, RAPD profiles of separate isolates of the same species demonstrated intra-species DNA amplimer size polymorphisms. However, these were more similar to the patterns obtained with other isolates of the same species than RAPD profiles derived from a different species. RAPD has many advantages over other molecular procedures for typing isolates of Candida, including simplicity, speed and large sample volume throughput. However, the reproducibility of RAPD depends on a number of factors, each of which must be controlled carefully if accurate and consistent results are to be obtained [79-81]. Furthermore, although nucleotide sequence information on the organisms being examined is not required, RAPD primers that yield informative profiles with isolates of one Candida spp. may not do so with another. RAPD primer(s) that yield informative fingerprint profiles with all the Candida spp. isolated regularly from clinical specimens have yet to be described. It remains to be seen whether such a universal primer(s) will be discovered.

Several recent studies have described the use of PCRrestriction fragment length polymorphism (PCRRFLP) analysis as a typing system for various bacterial species $[82,83]$. This process involves RFLP analysis of PCR amplimers obtained with primers complimentary to specific genomic DNA sequences. 
This approach may be useful for differentiating between isolates of Candida spp. but, as far as we are aware, no such studies have yet been reported.

\section{Application of molecular techniques to the taxonomy of Candida spp.}

While most Candida spp. that cause disease in man are being well-studied, little is understood of the natural relationships within the genus. The single major factor unifying the species of the genus is the absence of a detectable sexual stage. This is hardly a satisfactory foundation on which to base relationships between species which may be closely or more distantly related. Therefore, Candida taxonomy has relied largely on analysis of physical traits such as cell-wall properties, the ability to produce germ tubes, chlamydospores, pseudohyphae and true hyphae, and on physiological traits such as the ability to utilise a range of compounds as the sole source of carbon or nitrogen [1]. However, as phenotypic characteristics can vary considerably within some species, it is not surprising that there have been irregularities in the taxonomy of Candida [1,7,33, 56, 84-91]. Several recent studies have described isolates of Candida whose properties do not correspond precisely with classical species descriptions, thereby leading to further confusion $[18,88,92-$ 94]. All of the above considerations make the concept of species within the genus rather ambiguous. It is therefore timely to assess the potential contribution that other techniques could make to the elucidation of relationships between species of the genus Candida.

\section{Application of molecular techniques to resolving anomalies in Candida taxonomy}

Despite the absence of a sexual phase being a prerequisite for a species to be classified within the genus Candida, a few Candida spp., including $C$. krusei, C. guilliermondii, C. lusitaniae and C. kefyr have been found to be the asexual (anamorphic) forms of sexually reproductive (teleomorphic) yeasts [1]. However, these organisms are still classified within the genus. Although the relationships between these Candida spp. and their respective teleomorphic forms have been determined by classical chemotaxonomic techniques, the synonymy of $C$. krusei and Issatchenkia orientalis has been confirmed by comparing karyotype profiles and by hybridisation of a C. krusei-specific DNA probe to isolates of $I$. orientalis [50]. Clearly, the application of similar and other molecular techniques could also be used confirm the relationships between other Candida spp. and their respective teleomorphic counterparts, including $C$. kefyr and Kluyveromyces marxianus, C. lusitaniae and Clavispora lusitaniae, and C. guilliermondii and Pichia guilliermondii.

The precise relationship between $C$. albicans and two other closely related proposed species-C. clausenii (considered to be a germ-tube-negative mutant of $C$. albicans) and $C$. langeronii (considered to be a chlamydospore-negative mutant of $C$. albicans) - has long been questioned. However, this situation has been resolved by studies that compared karyotype profiles and DNA hybridisation patterns obtained with the $C$. albicans-specific fingerprinting probe $27 \mathrm{~A}$, which demonstrated conclusively that $C$. clausenii and $C$. langeronii are synonymous with $C$. albicans [50].

In contrast, the relationship between $C$. albicans and C. stellatoidea is more complicated. Karyotype and fingerprinting data suggest that there are two kinds of C. stellatoidea, termed types I and II [87]. Type II strains differ from $C$. albicans only in their inability to assimilate sucrose-and so are considered to be sucrose-negative variants of $C$. albicans-while type I strains, as well as being sucrose-negative also have karyotypes distinct from that of $C$. albicans and appear to be less virulent $[86,95]$. Although these data suggest that type I $C$. stellatoidea strains are not just simply mutant derivatives of $C$. albicans, they do not show sufficient differences from $C$. albicans to warrant species status. Therefore, it has been suggested that type I $C$. stellatoidea should be considered as a subspecies of $C$. albicans [1]. Further evidence in support of this designation is the very close homology between the sequence of the V3 region of the genes encoding the large ribosomal subunit of reference $C$. albicans and C. stellatoidea strains, in comparison with other Candida spp. [18].

We recently reported the isolation from HIV-infected individuals of atypical oral Candida isolates that produced chlamydospores and germ tubes. These features are usually diagnostic for $C$. albicans and C. stellatoidea, but the atypical isolates were not identifiable as either of these organisms on the basis of carbohydrate assimilation profiles [18, 33]. Furthermore, these organisms were unable to grow at $42^{\circ} \mathrm{C}$ and often produced chlamydospores that occurred in contiguous pairs or various multiples suspended from single suspensor cells, a feature that is quite unlike $C$. albicans [18]. Subsequent detailed molecular investigations-including karyotype analysis and DNA fingerprinting analysis of genomic DNA with: (i) the $C$. albicans-specific probe $27 \mathrm{~A}$ which hybridises efficiently to multiple fragments of $C$. albicans and $C$. stellatoidea genomic DNA; (ii) five separate oligonucleotide probes homologous to eukaryotic microsatellite sequences; and (iii) RAPD analysis with random sequence primers-demonstrated that the atypical Candida isolates had a genomic structure distinctly different from those of $C$. albicans and C. stellatoidea [18]. Furthermore, comparison of the nucleotide sequences of the V3 variable region of the large ribosomal subunit genes of several atypical isolates with the corresponding sequences of $C$. albicans, $C$. stellatoidea and several other non-albicans Candida spp. demonstrated that the atypical isolates were 
distinct phylogenetically and constituted a discrete taxon within the genus Candida for which the novel species name $C$. dubliniensis was proposed [18]. A particularly interesting feature of this proposed new species was its apparent relative genetic homogeneity in comparison to $C$. albicans isolates $[18,33]$. The isolates studied to date come from three sourcesDublin (Ireland), Melbourne (Australia) and the UKand this degree of homogeneity suggests strongly that this species may be the result of relatively recent evolutionary divergence.

In contrast with $C$. dubliniensis, several recent studies have demonstrated a wide degree of genetic heterogeneity within $C$. parapsilosis $[37,59,70,96,97]$. Two such studies-employing RAPD analysis, isoenzyme profile analysis and nucleotide sequence analysis of the ITS1 internally transcribed spacer sequences flanking the 5.8S RNA gene-have detected three distinct groups among $C$. parapsilosis clinical isolates $[37,97]$. Although further research is required, two of these groups show significant genetic dissimilarity from the type strain of $C$. parapsilosis and it is possible that they may represent distinct species or sub-species.

One of the most controversial aspects of the taxonomy of the genus Candida is its relationship with the genus Torulopsis. As is the case with Candida, Torulopsis is known as a 'form' genus comprising yeasts that are difficult to classify [1]. Yarrow and Meyer [98] proposed that the inability of Torulopsis spp. to form pseudohyphae was not by itself a sufficient criterion for the two genera to be separate, and that both should be considered to be a single genus with the name Candida (despite the historical precedence of Torulopsis). This determination has been accepted by most mycologists, although some still consider $C$. glabrata to be $T$. glabrata, and C. famata to be $T$. candida, preferring to adhere to the provisions of the International Code of Botanical Nomenclature $[99,100]$. A constructive contribution to this debate would be to perform an analysis of type strains of the Candida and Torulopsis genera, and possibly the Cryptococcus genus, by molecular techniques, of which the most appropriate method would be comparative nucleotide sequence analysis of ribosomal genes (see below).

\section{Molecular phylogenetic analysis}

Phylogenetic studies based on phenotypic characteristics alone have been shown to be unreliable [101]. Ribosomal DNA occurs in all living organisms and is ideally suited to the development of molecular phylogenies [102]. Indeed, comparative nucleotide sequence analysis of rDNA has been used extensively to study the evolutionary relationships among a wide variety of bacteria and, to a lesser extent, fungi [102-107]. Most of these studies have been performed on small ribosomal subunit gene sequences. A search of the EMBL and GenBank nucleotide sequence databases performed during August 1995 revealed that sequence data on small ribosomal subunit genes have been reported only for a limited number of Candida spp. and other ascomycetous yeasts, and not always for type strains. However, these studies indicate that small ribosomal subunit gene sequences can be used to confirm natural relationships within the genus, such as the close evolutionary relationship between $C$. albicans and $C$. tropicalis determined on the basis of biochemical and phenotypic criteria [107]. However, in order to achieve a detailed and unequivocal understanding of the evolutionary relationships between the species of the genus, additional extensive studies need to be performed with type strains from a wide range of Candida spp., including all species that have been isolated from human samples or have been reported as having the ability to cause disease in man.

Nucleotide sequence analysis of the V3 variable region of the large ribosomal subunit genes has provided very useful information concerning the phylogenetic relationships between various marine yeasts $[108,109]$. Similarly, the phylogenetic analysis performed in the study of $C$. dublinensis isolates highlighted the potential of this approach to develop an unequivocal phylogeny for members of the genus Candida that cause infection in man [18]. Comparison of $500 \mathrm{bp}$ of the V3 variable region of the large ribosomal subunit genes from nine $C$. dubliniensis isolates - from Dublin, Australia and the UK-and the corresponding sequences determined from C. albicans, C. stellatoidea, C. tropicalis, C. parapsilosis, C. glabrata, C. kefyr and C. krusei demonstrated clearly that the C.dubliniensis isolates formed a homogenous cluster $(100 \%$ similarity) that differed significantly from the isolates of the other Candida spp. analysed. It also demonstrated that type I $C$. stellatoidea shares very close homology with $C$. albicans in comparison with the other Candida spp., thereby providing further support for its designation as a subspecies of $C$. albicans [18].

\section{Conclusions}

With the use of suitable culture media and careful analysis of phenotypic and metabolic tests, it is feasible to obtain with reasonable precision an identification of most non-albicans Candida spp. Molecular techniques will soon be sufficiently simple, rapid and specific to be considered as first line tests. $C$. dubliniensis provides a cautionary lesson in this respect because examination of an isolate listed as $C$. stellatoidea from a culture collection (strain NCPF3108) by the traditional techniques indicated that it was similar to $C$. dubliniensis. Only when other $C$. stellatoidea type strains were examined by traditional and molecular techniques was it possible to differentiate the three 
organisms. However well maintained they are, Candida isolates from culture collections need to have their identify verified as stringently as any clinical isolate. The majority of our $C$. dubliniensis isolates came from HIV-infected intravenous drug users, but as the study of C. dubliniensis progressed, additional isolates were found among stored collections from different groups of HIV-infected patients and from other sources, such as a vaginal specimen from a woman presenting with vaginitis, an oral specimen from a diabetic patient and several oral isolates from normal healthy individuals. Atypical Candida isolates from HIV-infected Australian subjects were included in the characterisation of the novel species $C$. dubliniensis, and similar isolates have been obtained from HIV-infected intravenous drug users in Switzerland and from AIDS patients in the UK. It seems that this organism has been present in several different clinical settings and in a number of countries for some time, and that it has been classed as an unusual $C$. albicans or $C$. sake. It is hoped that this example will provide the stimulus for a systematic reassessment of the methods for identifying organisms isolated from cases of candidosis. However, the precise combination of features-genetic and phenotypic - that will be acceptable in the future to distinguish the genus Candida from other asporogenic yeasts, and to distinguish one species of Candida from another, remains to be determined.

These studies were supported by the Irish Health Research Board (HRB) Opportunistic Infection in AIDS Programme grant and a HRB grant to study oral candidosis in HIV-infected and non-infected haemophiliacs. Support for L.O'N. and G.M. was provided by Trinity College Dublin and the School of Dental Science and Dublin Dental Hospital (DDH). We thank Dr Christine McCreary and Dr B. Harrington from DDH for providing clinical specimens.

\section{References}

1. Odds FC. Pathogenesis of candidosis. In: Odds FC (ed) Candida and candidosis, 2nd edn. London, Baillière Tindall. 1988.

2. Powderly WG. Mucosal candidiasis caused by non-albicans species of Candida in HIV-positive patients. AIDS 1992; 6: 604-605.

3. Coleman DC, Bennett DE, Gallagher PJ et al. Oral candidiasis and HIV infection; antifungal drug resistance and changes in Candida population dynamics. In: Greenspan JS, Greenspan D (eds) Oral manifestations of HIV infection Chicago, Quintessence Publishing Co., Inc. 1995: 112-118.

4. Johnson EM, Warnock DW, Luker J, Porter SR, Scully C. Emergence of azole drug resistance in Candida species from HIV-infected patients receiving prolonged fluconazole therapy for oral candidosis. J Antimicrob Chemother 1995; 35: 103114.

5. Ruhnke M, Eigler A, Engelmann E, Geiseler B, Trautmann M. Correlation between antifungal susceptibility testing of Candida isolates from patients with HIV infection and clinical results after treatment with fluconazole. Infection 1994; 22: 132-136.

6. Rex JH, Rinaldi MG, Pfaller MA. Resistance of Candida species to fluconazole. Antimicrob Agents Chemother 1995; 39: $1-8$.

7. Coleman DC, Bennett DE, Sullivan DJ et al. Oral Candida in HIV infection and AIDS: new perspectives/new approaches. Crit Rev Microbiol 1993; 19: 61-82.

8. Millon L, Manteaux A, Reboux G et al. Fluconazole-resistant recurrent oral candidiasis in human immunodeficiency virus- positive patients: persistence of Candida albicans strains with the same genotype. J Clin Microbiol 1994; 32: 1115-1118.

9. Barnett JA, Payne RW, Yarrow D. Descriptions of the species arranged alphabetically. In: Barnett JA, Payne RW, Yarrow D (eds) Yeasts: characteristics and identification, 2nd edn. Cambridge, Cambridge University Press. 1990: 79-695.

10. Samaranayake LP. Oral mycoses in HIV infection. Oral Surg Oral Med Oral Pathol 1992; 73: 171-180.

11. Pfaller MA. Epidemiology and control of fungal infections Clin Infect Dis 1994; 19 Suppl 1: S8-13.

12. Horn R, Wong B, Kiehn TE, Armstrong D. Fungemia in a cancer hospital: changing frequency, earlier onset, and results of therapy. Rev Infect Dis 1985; 7: 646-655.

13. Soll DR, Staebell M, Langtimm C, Pfaller M, Hicks J, Rao TVG. Multiple Candida strains in the course of a single systemic infection. J Clin Microbiol 1988; 26: 1448-1459.

14. Wingard JR, Merz WG, Rinaldi MG, Johnson TR, Karp JE, Saral R. Increase in Candida krusei infection among patients with bone marrow transplantation and neutropenia treated prophylactically with fluconazole. $N$ Engl $J$ Med 1991; 325: 1274-1277.

15. Sanchez V, Vazquez JA, Barth-Jones D, Dembry L, Sobel JD, Zervos MJ. Epidemiology of nosocomial acquisition of Candida lusitaniae. J Clin Microbiol 1992; 30: 3005-3008.

16. Law D, Moore CB, Wardle HM, Ganguli LA, Keaney MGL, Denning DW. High prevalence of antifungal resistance in Candida spp. from patients with AIDS. $J$ Antimicrob Chemother 1994; 34: 659-668.

17. Samaranayake YH, Samaranayake LP. Candida krusei biology, epidemiology, pathogenicity and clinical manifestations of an emerging pathogen. $J$ Med Microbiol 1994; 41 $295-310$.

18. Sullivan DJ, Westerneng TJ, Haynes KA, Bennett DE, Coleman DC. Candida dubliniensis sp. nov: phenotypic and molecular characterization of a novel species associated with oral candidosis in HIV-infected individuals. Microbiology 1995; 141: $1507-1521$.

19. Alsina A, Mason M, Uphoff RA, Riggsby WS, Becker JM, Murphy D. Catheter-associated Candida utilis fungemia in a patient with acquired immunodeficiency syndrome: species verification with a molecular probe. J Clin Microbiol 1988 26: $621-624$

20. Holmberg $\mathrm{K}$, Meyer RD. Fungal infections in patients with AIDS and AIDS-related complex. Scand J Infect Dis 1986 18: $179-192$

21. Tavitian A, Raufman J-P, Rosenthal LE. Oral candidiasis as a marker for esophageal candidiasis in the acquired immunodeficiency syndrome. Ann Intern Med 1986; 104: 54-55.

22. Warnock DW. Azole drug resistance in Candida species. J Med Microbiol 1992; 37: 225-226.

23. Odds FC. Sabouraud('s) agar. J Med Vet Mycol 1991; 29 355-359.

24. Samaranayake LP, MacFarlane TW, Williamson MI. Comparison of Sabouraud dextrose and Pagano-Levin agar media for detection and isolation of yeasts from oral samples. $\mathrm{J}$ Clin Microbiol 1987; 25: 162-164.

25. Pagano J, Levin JD, Trejo W. Diagnostic medium for differentiation of species of Candida. Antibiot Ann 1958; 1957-58: $137-143$.

26. Costa SOP, de Lourdes Branco C. Evaluation of a molybdenum culture medium as selective and differential for yeasts. J Pathol Bacteriol 1964; 87: 428-431.

27. Bump CM, Kunz LJ. Routine identification of yeasts with the aid of molybdate-agar medium. Appl Microbiol 1968; 16: 1503-1506.

28. Nickerson WJ. Reduction of inorganic substances by yeasts. I. Extracellular reduction of sulfite by species of Candida. $J$ Infect Dis 1953; 93: 43-56.

29. Odds FC, Bernaerts R. CHROMagar Candida, a new differential isolation medium for presumptive identification of clinically important Candida species. J Clin Microbiol 1994; 32: 1923-1929.

30. Hunter PR, Fraser CAM. Application of a numerical index of discriminatory power to a comparison of four physiochemical typing methods for Candida albicans. J Clin Microbiol 1989; 27: $2156-2160$

31. Berger SA. Lack of precision in commercial identification systems: correction using Bayesian analysis. J Appl Bacteriol 1990; 68: 285-288.

32. Gallagher PJ, Bennett DE, Henman MC et al. Reduced azole 
susceptibility of oral isolates of Candida albicans from HIVpositive patients and a derivative exhibiting colony morphology variation. J Gen Microbiol 1992; 138: 1901-1911.

33. Sullivan D, Bennett D, Henman $\mathrm{M}$ et al. Oligonucleotide fingerprinting of isolates of Candida species other than $C$. albicans and of atypical Candida species from human immunodeficiency virus-positive and AIDS patients. $J$ Clin Microbiol 1993; 31: 2124-2133.

34. Magee BB, D'Souza TM, Magee PT. Strain and species identification by restriction fragment length polymorphisms in the ribosomal DNA repeat of Candida species. $J$ Bacteriol 1987; 169: 1639-1643.

35. Mason MM, Lasker BA, Riggsby WS. Molecular probe for identification of medically important Candida species and Torulopsis glabrata. J Clin Microbiol 1987; 25: 563-566.

36. Monod M, Porchet S, Baudraz-Rosselet F, Frenk E. The identification of pathogenic yeast strains by electrophoretic analysis of their chromosomes. J Med Microbiol 1990; 32: 123-129.

37. Lehmann PF, Lin D, Lasker BA. Genotypic identification and characterization of species and strains within the genus Candida by using random amplified polymorphic DNA. $J$ Clin Microbiol 1992; 30: 3249-3254.

38. Miyakawa $Y$, Mabuchi $T$, Kagaya $K$, Fukazawa $Y$. Isolation and characterization of a species-specific DNA fragment for detection of Candida albicans by polymerase chain reaction. J Clin Microbiol 1992; 30: 894-900.

39. Crampin AC, Matthews RC. Application of the polymerase chain reaction to the diagnosis of candidosis by amplification of an HSP 90 gene fragment. J Med Microbiol 1993: 39: 233-238.

40. Niesters HGM, Goessens WHF, Meis JFMG, Quint WGV. Rapid, polymerase chain reaction-based identification assays for Candida species. J Clin Microbiol 1993; 31: 904-910.

41. Burgener-Kainuz P, Zuber J-P, Jaunin P, Buchman TG, Bille J, Rossier M. Rapid detection and identification of Candida albicans and Torulopsis (Candida) glabrata in clinical specimens by species-specific nested PCR amplification of a cytochrome P-450 lanosterol- $\alpha$-demethylase (L1A1) gene fragment. J Clin Microbiol 1994; 32: 1902-1907.

42. Carlotti A, Grillot R, Couble A, Villard J. Typing of Candida krusei clinical isolates by restriction endonuclease analysis and hybridization with $\mathrm{CkF1}, 2$ DNA probe. $J$ Clin Microbiol 1994; 32: 1691-1699.

43. Check WA. Molecular techniques shed light on fungal genetics. ASM News 1994; 60: 593-596.

44. Holmes AR, Cannon RD, Shepherd MG, Jenkinson HF. Detection of Candida albicans and other yeasts in blood by PCR. J Clin Microbiol 1994; 32: 228-231.

45. Fujita S-I, Lasker BA, Lott TJ, Reiss E, Morrison CJ. Microtitration plate enzyme immunoassay to detect PCRamplified DNA from Candida species in blood. $J$ Clin Microbiol 1995; 33: 962-967.

46. Scherer S, Stevens DA. Application of DNA typing methods to epidemiology and taxonomy of Candida species. $J$ Clin Microbiol 1987; 25: 675-679.

47. Matthews R, Burnie J. Assessment of DNA fingerprinting for rapid identification of outbreaks of systemic candidiasis. $B M J$ 1989; 298: 354-357.

48. Scherer S, Stevens DA. A Candida albicans dispersed, repeated gene family and its epidemiologic applications. Proc Natl Acad Sci USA 1988; 85: 1452-1456.

49. Soll DR, Langtimm CJ, McDowell J, Hicks J, Galask R. High-frequency switching in Candida strains isolated from vaginitis patients. J Clin Microbiol 1987; 25: 1611-1622.

50. Wickes BL, Hicks JB, Merz WG, Kwon-Chung KJ. The molecular analysis of synonymy among medically importan yeasts within the genus Candida. J Gen Microbiol 1992; 138: 901-907.

51. Cheung LL, Hudson JB. Development of DNA probes for Candida albicans. Diagn Microbiol Infect Dis 1988: 10: 171179

52. Holmes AR, Lee YC, Cannon RD, Jenkinson HF, Shepherd MG. Yeast-specific DNA probes and their application for the detection of Candida albicans. J Med Microbiol 1992; 37: 346-351

53. Santos MAS, el-Adlouni C, Cox AD, Luz JM, Keith G, Tuite MF. Transfer RNA profiling: a new method for the identification of pathogenic Candida species. Yeast 1994; 10: $625-636$.
54. Saiki RK, Scharf S, Faloona $F$ et al. Enzymatic amplification of $\beta$-globin genomic sequences and restriction site analysis for diagnosis of sickle cell anemia. Science 1985; 230: 1350 1354.

55. Botelho AR, Planta RJ. Specific identification of Candida albicans by hybridization with oligonucleotides derived from ribosomal DNA internal spacers. Yeast 1994; 10: 709-717.

56. Odds FC, Merson-Davies LA. Colony variations in Candida species. Mycoses 1989; 32: 275-282.

57. Smith RA, Hitchcock CA, Evans EGV, Lacey CJN, Adams DJ. The identification of Candida albicans strains by restriction fragment length polymorphism analysis of DNA $J$ Med Vet Mycol 1989; 27: 431-434.

58. Doebbeling BN, Lehmann PF, Hollis RJ et al. Comparison of pulsed-field gel electrophoresis with isoenzyme profiles as a typing system for Candida tropicalis. Clin Infect Dis 1993; 16: $377-383$.

59. Branchini ML, Pfaller MA, Rhine-Chalberg J, Frempong T, Isenberg HD. Genotypic variation and slime production among blood and catheter isolates of Candida parapsilosis. $J$ Clin Microbiol 1994; 32: 452-456.

60. King D, Rhine-Chalberg J, Pfaller MA, Moser SA, Merz WG Comparison of four DNA-based methods for strain delineation of Candida lusitaniae. J Clin Microbiol 1995; 33: 1467 1470.

61. Fox BC, Mobley HLT, Wade JC. The use of a DNA probe for epidemiological studies of candidiasis in immunocompromised hosts. I Infect Dis 1989; 159: 488-494.

62. Schmid J, Odds FC, Wiselka MJ, Nicholson KG, Soll DR. Genetic similarity and maintenance of Candida albicans strains from a group of AIDS patients, demonstrated by DNA fingerprinting. J Clin Microbiol 1992; 30: 935-941.

63. Tautz D, Renz M. Simple sequences are ubiquitous repetitive components of eukaryotic genomes. Nucleic Acids Res 1984; 12: $4127-4138$.

64. Meyer W, Koch A, Niemann C, Beyermann B, Epplen JT, Börner T. Differentiation of species and strains among filamentous fungi by DNA fingerprinting. Curr Genet 1991; 19: $239-242$

65. Meyer W, Morawetz R, Börner T, Kubicek CP. The use of DNA-fingerprint analysis in the classification of some species of the Trichoderma aggregate. Curr Genet 1992; 21: 27-30.

66. Wilkinson BM, Morris L, Adams DJ, Evans EGV, Lacey CJN, Walmsley RM. A new, sensitive polynucleotide probe for distinguishing Candida albicans strains and its use with a computer assisted archiving and pattern comparison system. $J$ Med Vet Mycol 1992; 30: 123-131.

67. Haynes KA, Sullivan DJ, Coleman DC et al. Involvement of multiple Cryptococcus neoformans strains in a single episode of cryptococcosis and reinfection with novel strains in recurrent infection demonstrated by random amplification of polymorphic DNA and DNA fingerprinting. $J$ Clin Microbiol 1995; 33: 99-102.

68. Magee BB, Magee PT. Electrophoretic karyotypes and chromosome numbers in Candida species. $J$ Gen Microbiol 1987; 133: 425-430.

69. Asakura K, Iwaguchi S-I, Homma M, Sukai T, Higashide K, Tanaka K. Electrophoretic karyotypes of clinically isolated yeasts of Candida albicans and C. glabrata. J Gen Microbiol 1991; 137: 2531-2538.

70. Carruba G, Pontieri E, De Bernardis F, Martino P, Cassone A DNA fingerprinting and electrophoretic karyotypes of environmental and clinical isolates of Candida parapsilosis. $J$ Clin Microbiol 1991; 29: 916-922.

71. Khattak MN, Burnie JP, Matthews RC, Oppenheim BA. Clamped homogeneous electric field gel electrophoresis typing of Torulopsis glabrata isolates causing nosocomial infections. J Clin Microbiol 1992; 30: 2211-2215.

72. Merz WG, Khazan U, Jabra-Rizk MA, Wu L-C, Osterhout GJ, Lehmann PF. Strain delineation and epidemiology of Candida (Clavispora) lusitaniae. J Clin Microbiol 1992; 30 449-454.

73. Vazquez JA, Beckley A, Donabedian S, Sobel JD, Zervos MJ. Comparison of restriction enzyme analysis versus pulsed-field gradient gel electrophoresis as a typing system for Torulopsis glabrata and Candida species other than C. albicans. J Clin Microbiol 1993; 31: 2021-2030.

74. Bostock A, Khattak MN, Matthews R, Burnie J. Comparison of PCR fingerprinting, by random amplification of polymorphic DNA, with other molecular typing methods for 
Candida albicans. J Gen Microbiol 1993; 139: 2179-2184.

75. Welsh J, McClelland M. Fingerprinting genomes using PCR with arbitrary primers. Nucleic Acids Res 1990; 18: 7213 7218.

76. Williams JGK, Kubelik AR, Livak KJ, Rafalski JA, Tingey SV. DNA polymorphisms amplified by arbitrary primers are useful as genetic markers. Nucleic Acids Res 1990; 18: 65316535.

77. Welsh J, McClelland M. Genomic fingerprinting using arbitrarily primed PCR and a matrix of pairwise combinations of primers. Nucleic Acids Res 1991; 19: 5275-5279.

78. van Belkum A. DNA fingerprinting of medically important microorganisms by use of PCR. Clin Microbiol Rev 1994; 7 : 174-184.

79. Coutinho HLC, Handley BA, Kay HE, Stevenson L, Beringer JE. The effect of colony age on PCR fingerprinting. Lett Appl Microbiol 1993; 17: 282-284.

80. Venugopal G, Mohapatra S, Salo D, Mohapatra S. Multiple mismatch annealing: basis for random amplified polymorphic DNA fingerprinting. Biochem Biophys Res Commun 1993; 197: 1382-1387.

81. Cobb BD, Clarkson JM. A simple procedure for optimising the polymerase chain reaction (PCR) using modified Taguchi methods. Nucleic Acids Res 1994; 22: 3801-3805.

82. Ralph D, McClelland M, Welsh J, Baranton G, Perolat P. Leptospira species categorized by arbitrarily primed polymerase chain reaction (PCR) and by mapped restriction polymorphisms in PCR-amplified rRNA genes. $J$ Bacteriol 1993; 175: 973-981.

83. Taylor NS, Fox JG, Akopyants NS et al. Long-term colonization with single and multiple strains of Helicobacter pylori assessed by DNA fingerprinting. J Clin Microbiol 1995; 33: 918-923.

84. Akisada T, Harada K, Niimi M, Kamaguchi A. Production of contiguously arranged chlamydospores in Candida albicans. $J$ Gen Microbiol 1983; 129: 2327-2330.

85. Williamson MI, Samaranayake LP, MacFarlane TW. Biotypes of oral Candida albicans and Candida tropicalis isolates. $J$ Med Vet Mycol 1986; 24: 81-84.

86. Kwon-Chung KJ, Wickes BL, Merz WG. Association of electrophoretic karyotype of Candida stellatoidea with virulence for mice. Infect Immun 1988; 56: 1814-1819.

87. Kwon-Chung KJ, Riggsby WS, Uphoff RA et al. Genetic differences between type I and type II Candida stellatoidea. Infect Immun 1989; 57: 527-532.

88. Mahrous M, Lott TJ, Meyer SA, Sawant AD, Ahearn DG. Electrophoretic karyotyping of typical and atypical Candida albicans. J Clin Microbiol 1990; 28: 876-881.

89. Martinez JP, Gilm L, Casanova M, Ribot-Lopez JL, DeLomas JG, Sentandreu R. Wall mannoproteins in cells from colonial phenotypic variants of Candida albicans. J Gen Microbiol 1990; 136: 2421-2432.

90. Ghannoum MA, Swairjo I, Soll DR. Variation in lipid and sterol contents in Candida albicans white and opaque phenotypes. J Med Vet Mycol 1990; 28: 103-115.

91. Wickes BL, Golin JE, Kwon-Chung KJ. Chromosomal rearrangement in Candida stellatoidea results in a positive effect on phenotype. Infect Immun 1991; 59: 1762-1771.
92. McCullough MJ, Ross BC, Dwyer BD, Reade PC. Genotype and phenotype of oral Candida albicans from patients infected with the human immunodeficiency virus. Microbiology 1994; 140: 1195-1202.

93. McCullough M, Ross B, Reade P. Characterization of genetically distinct subgroup of Candida albicans strains isolated from oral cavities of patients infected with the human immunodeficiency virus. J Clin Microbiol 1995; 33: 696-700.

94. Boerlin P, Boerlin-Petzold F, Durussel C et al. Cluster of oral atypical Candida albicans isolates in a group of human immunodeficiency virus-positive drug users. J Clin Microbiol 1995; 33: 1129-1135.

95. Kwon-Chung KJ, Hicks JB, Lipke PN. Evidence that Candida stellatoidea type II is a mutant of Candida albicans that does not express sucrose-inhibitable $\alpha$-glucosidase. Infect Immun 1990; 58: 2804-2808.

96. Lott TJ, Kuykendall RJ, Welbel SF, Pramanik A, Lasker BR. Genomic heterogeneity in the yeast Candida parapsilosis. Curr Genet 1993; 23: 463-467.

97. Lin D, Wu L-C, Rinaldi MG, Lehmann PF. Three distinct genotypes within Candida parapsilosis from clinical sources. J Clin Microbiol 1995; 33: 1815-1821.

98. Yarrow D, Meyer SA. Proposal for-amendment of the diagnosis of the genus Candida Berkhout nom. cons. Int $J$ Syst Bacteriol 1978; 28: 611-615.

99. McGinnis MR, Ajello L, Beneke ES et al. Taxonomic and nomenclatural evaluation of the genera Candida and Torulopsis. J Clin Microbiol 1984; 20: 813-814.

100. Odds FC. Candida albicans, the life and times of a pathogenic yeast. $J$ Med Vet Mycol 1994; 32 Suppl 1: 1-8.

101. Kurtzman CP, Phaff HJ. Molecular taxonomy. In: Rose AH, Harrison JS (eds) The yeasts, vol 1. Biology of yeasts, 2nd edn. London, Academic Press. 1987: 63-94.

102. Woese CR. Bacterial evolution. Microbiol Rev 1987; 51: 221271.

103. Sogin ML, Miotto K, Miller L. Primary structure of the Neurospora crassa small subunit ribosomal RNA coding region. Nucleic Acids Res 1986; 14: 9540.

104. Edman JC, Kovacs JA, Masur H, Santi DV, Elwood HJ, Sogin ML. Ribosomal RNA sequence shows Pneumocystis carinii to be a member of the fungi. Nature 1988; 334: 519-522.

105. Wong OC, Clark-Walker GD. Sequence of the gene for the cytoplasmic ribosomal RNA small subunit from Candida (Torulopsis) glabrata. Nucleic Acids Res 1990; 18: 1888.

106. Barns SM, Lane DJ, Sogin ML, Bibeau C, Weisburg WG. Evolutionary relationships among pathogenic Candida species and relatives. $J$ Bacteriol 1991; 173: 2250-2255.

107. Hendriks L, Goris A, Van de Peer Y et al. Phylogenetic analysis of five medically important Candida species as deduced on the basis of small ribosomal subunit RNA sequences. J Gen Microbiol 1991; 137: 1223-1230.

108. Fell JW, Statzell-Tallman A, Lutz MJ, Kurtzman CP. Partial rRNA sequences in marine yeasts; a model for identification of marine eukaryotes. Mol Mar Biol Biotechnol 1992; 1: $175-186$.

109. Fell JW. Rapid identification of yeast species using three primers in a polymerase chain reaction. Mol Mar Biol Biotechnol 1993; 2: 174-180. 